\title{
Stereotactic body radiation therapy for the primary treatment of localized prostate cancer
}

\author{
Caspian Oliai • Rachelle Lanciano • Brian Sprandio • \\ Jun Yang • John Lamond • Steven Arrigo • \\ Michael Good • Michael Mooreville • Bruce Garber • \\ Luther W. Brady
}

Received: 4 June 2012 / Accepted: 30 August 2012 / Published online: 12 September 2012

(C) The Author(s) 2012. This article is published with open access at Springerlink.com

\begin{abstract}
Objective The low alpha/beta ratio of prostate cancer suggests that hypofractionated schemes of dose-escalated radiotherapy should be advantageous. We report our experience using stereotactic body radiation therapy (SBRT) for the primary treatment of prostate cancer to assess efficacy and toxicity.

Methods From 2007 to 2010, 70 patients (51 \% low risk, $31 \%$ intermediate risk, and $17 \%$ high risk) with localized prostate cancer were treated with SBRT using the CyberKnife system. One-third of patients received androgen deprivation therapy. Doses of 37.5 Gy $(n=29), 36.25$ Gy $(n=36)$, and 35 Gy $(n=5)$ were administered in five fractions and analyzed as high dose (37.5 Gy) vs. low dose (36.25 and 35 Gy).

Results At a median 27 and 37 months follow-up, the low and high dose groups' median PSA nadir to date was 0.3 and $0.2 \mathrm{ng} / \mathrm{ml}$, respectively. The 3-year freedom from biochemical failure (FFBF) was $100 \%, 95.0 \%$ and $77.1 \%$ for the low-, intermediate- and high-risk patients. A dose response was observed in intermediate- and high-risk patients with $72 \%$ vs. $100 \%$ 3-year FFBF for the low and high dose groups, respectively $(p=0.0363)$. Grade III genitourinary
\end{abstract}

C. Oliai $\cdot$ R. Lanciano $\cdot$ J. Yang $\cdot$ J. Lamond $\cdot$ B. Garber $\cdot$

L. W. Brady

Drexel University College of Medicine/Hahnemann

University Hospital,

230 N Broad St,

Philadelphia, PA 19102, USA

C. Oliai $\cdot$ R. Lanciano $(\bowtie) \cdot$ B. Sprandio $\cdot J$. Yang $\cdot J$. Lamond $\cdot$

S. Arrigo $\cdot$ M. Good $\cdot$ M. Mooreville $\cdot$ L. W. Brady

Philadelphia CyberKnife Center,

2010 West Chest Pike Suite 115,

Havertown, PA 19083, USA

e-mail: rlancmd@gmail.com toxicities included $4 \%$ acute and $3 \%$ late (all high dose). Potency was preserved in $83 \%$ of hormone naïve patients. Conclusion CyberKnife dose escalated SBRT for low-, intermediate- and high-risk prostate cancer exhibits favorable efficacy with acceptable toxicity.

Keywords Stereotactic body radiation therapy - Prostate cancer $\cdot$ Hypofractionation $\cdot$ Alpha/beta ratio $\cdot$ Dose escalation

\section{Introduction}

Technological and radiobiological advances in early-stage prostate cancer treatment have led to a debate within the radiation oncology community over the optimal treatment. Long-term results from prospective $[1,2]$ and randomized dose escalation trials [3-5], comparing doses of 74-81 Gy to doses $<70$ Gy show dose escalation with conventional fractionation (1.8-2.0 Gy per fraction) improves freedom from biochemical failure (FFBF) and disease progression with acceptable toxicity. However, despite dose escalation, improvements are needed to consistently achieve the highest outcomes.

Brenner and Hall [6] suggested hypofractionation for prostate cancer as an alternative radiation scheme based on radiobiological modeling from external beam radiation therapy (EBRT) and low-dose rate brachytherapy series. They estimated that the alpha/beta $(\alpha / \beta)$ ratio for prostate cancer was uniquely low at $1.5 \mathrm{~Gy}$ as opposed to about $10 \mathrm{~Gy}$ for other cancers. An $\alpha / \beta$ ratio $<2$ Gy would be clinically significant since late-responding normal tissue near the prostate has an $\alpha / \beta$ ratio between 2 and 4 Gy. Therefore, a hypofractionated dose scheme has the potential to produce a more advantageous therapeutic ratio. The low $\alpha / \beta$ ratio for 
prostate cancer is supported by Fowler et al. [7], who suggested that it may be as low or even lower than $1.5 \mathrm{~Gy}$. Trials designed to assess these estimates showed that moderately hypofractionated doses were superior to conventional fractionation with respect to biochemical control and survival with acceptable levels of toxicity [8-10]. Indeed, reviews of clinical datasets support a mean $\alpha / \beta$ ratio $<1.5$ Gy $[11,12]$.

High dose-rate (HDR) brachytherapy has shown excellent hypofractionated monotherapy results [13], however, limitations on its use include clinical experience, technology availability and patient participation in an invasive procedure. Stereotactic body radiotherapy (SBRT), typically five fractions, is also well suited for hypofractionated radiation delivery. Several recent SBRT publications report promising clinical efficacy with minimal toxicity, including series with 5 years follow-up [14-22]. Furthermore, possible reduced cost and patient convenience make SBRT a desirable treatment modality. We report on intermediate-term toxicity and efficacy of our SBRT experience for early stage prostate cancer.

\section{Methods}

Eighty-three early stage prostate cancer patients received SBRT at the Philadelphia CyberKnife Center from 2007 through 2010. Patients with $\geq 12$ months of follow-up are included in this IRB approved retrospective analysis. SBRT was delivered using the CyberKnife (Accuray Inc., Sunnyvale, CA) with MultiPlan inverse treatment planning and motion tracking of internal fiducials. Treatment planning began with transrectal or transperineal ultrasound-guided placement of four gold fiducials into the prostate. A CT scan (1.25-mm slice thickness) was obtained 10-14 days later to allow inflammation to subside and ensure fiducials did not migrate. T2 fast echo MRI was obtained and threedimensionally registered by fiducials to the $\mathrm{CT}$ in the majority of patients.

The prostate, seminal vesicles, rectum, bladder, penile bulb, and bowel were contoured (Fig. 1). Urethra contouring was preferred, but not required. The clinical target volume (CTV) was the prostate for low-risk patients and the prostate plus 2-cm seminal vesicle base for four intermediate-risk and two high-risk patients. All of the other intermediate- and highrisk patients had a CTV which encompassed the prostate without the seminal vesicle bases. A total dose of $35,36.25$ or $37.5 \mathrm{~Gy}$, delivered in five fractions, was prescribed to the planning target volume (PTV) that consisted of the CTV with a 5-mm margin in all directions except $3 \mathrm{~mm}$ posteriorly. Dose administered was standard throughout our center, which was based on published data available at that time. Initially, we treated patients with $35 \mathrm{~Gy}$, followed by $37.5 \mathrm{~Gy}$, and at the

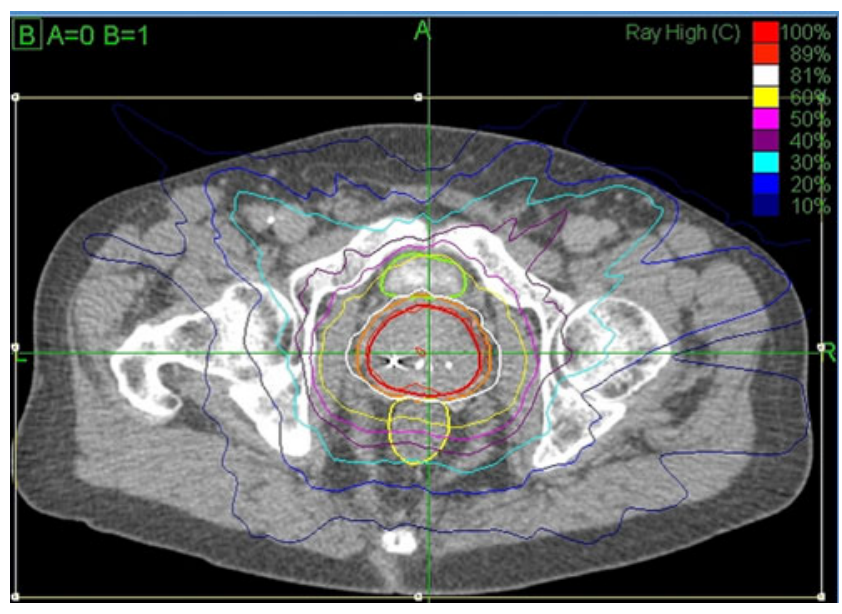

Fig. 1 CyberKnife SBRT treatment plan $(36.25$ Gy $\times 5$ fractions prescribed to the $81 \%$ isodose line (white) with a 44.75 Gy maximum dose. Shown are the prostate $\left(43.6 \mathrm{~cm}^{3}\right.$, red $)$ and PTV $\left(77.8 \mathrm{~cm}^{3}\right.$, orange). A bladder (green) volume of $1.66 \mathrm{~cm}^{3}$ received $37 \mathrm{~Gy}$ and $0.4 \mathrm{~cm}^{3}$ of the rectum (yellow) received $36 \mathrm{~Gy}$

time of this publication to $36.25 \mathrm{~Gy}$, which began when we participated in an Accuray Inc study. The dosimetric goal was to cover at least $95 \%$ of the PTV with the prescribed dose normalized to the $75-85 \%$ isodose line (dose heterogeneity $17-33 \%$ ). Less than $1 \mathrm{~cm}^{3}$ of rectum received $36 \mathrm{~Gy}, 50 \%$ of the prescribed dose could not cross the posterior rectal wall, and $<10 \mathrm{~cm}^{3}$ of bladder received $37 \mathrm{~Gy}$. The average CTV and PTV were $55.0 \mathrm{~cm}^{3}$ (std dev $27.5 \mathrm{~cm}^{3}$ ) and $95.4 \mathrm{~cm}^{3}$ (std dev $41.3 \mathrm{~cm}^{3}$ ), respectively.

Orthogonal $120-\mathrm{kV}$ X-ray image pairs were obtained throughout treatment for use in motion tracking. The realtime prostate position was locked-on by the relative fiducial position on the X-rays. For those patients with evenly distributed fiducials in the prostate quadrants, the prostate's rotation was also tracked and corrections were made in real time.

PSA nadir to date is defined as the lowest PSA value following SBRT. Benign PSA bounce was defined as a PSA rise of $\geq 0.2 \mathrm{ng} / \mathrm{ml}$ above its previous nadir with subsequent decline to that nadir or lower. Biochemical failure (BF) was assessed using the nadir +2 (Phoenix) definition. Toxicity was assessed using the Radiation Therapy Oncology Group criteria; acute toxicity occurred within 3 months and late toxicity $>3$ months following treatment. Risk group was assessed with the AUA system. Unpaired $t$-tests assessed statistical significance.

\section{Results}

Patient and treatment characteristics

Seventy patients with a median 31 months (range 13-51) follow-up were analyzed (Table 1) including one patient 
Table 1 Patient and tumor characteristics

\begin{tabular}{|c|c|c|c|}
\hline & All patients & High dose & Low dose \\
\hline Number & 70 & 29 & 41 \\
\hline \multicolumn{4}{|l|}{ Dose $(n)$} \\
\hline 35 Gy & 5 & 0 & 5 \\
\hline 36.25 Gy & 36 & 0 & 36 \\
\hline $37.5 \mathrm{~Gy}$ & 29 & 29 & 0 \\
\hline \multicolumn{4}{|l|}{ Age (years) } \\
\hline Median (range) & $68(46-88)$ & $67(46-80)$ & $68(51-88)$ \\
\hline \multicolumn{4}{|l|}{$\mathrm{CTV}\left(\mathrm{cm}^{3}\right)$} \\
\hline Median (range) & $47.5(19.0-162.2)$ & $49.87(31.6-162.2)$ & $44.4(19.0-107.9)$ \\
\hline \multicolumn{4}{|l|}{ iPSA (ng/ml) } \\
\hline Median (range) & $5.6(1.1-39.4)$ & $5.7(1.1-29.5)$ & $5.6(1.6-39.4)$ \\
\hline \multicolumn{4}{|l|}{ Tumor stage $(n / \%)$} \\
\hline $\mathrm{T} 1 \mathrm{~b}$ & 1 & $0 / 0 \%$ & $1 / 2 \%$ \\
\hline $\mathrm{T} 1 \mathrm{c}$ & 52 & $21 / 73 \%$ & $31 / 77 \%$ \\
\hline $\mathrm{T} 2 \mathrm{a}$ & 7 & $5 / 17 \%$ & $2 / 4 \%$ \\
\hline $\mathrm{T} 2 \mathrm{~b}$ & 4 & $3 / 10 \%$ & $1 / 2 \%$ \\
\hline $\mathrm{T} 2 \mathrm{c}$ & 6 & $0 / 0 \%$ & $6 / 15 \%$ \\
\hline \multicolumn{4}{|c|}{ Gleason score $(n / \%)$} \\
\hline 5 & 2 & $1 / 3 \%$ & $1 / 2 \%$ \\
\hline 6 & 39 & $15 / 52 \%$ & $24 / 59 \%$ \\
\hline 7 & 23 & $10 / 35 \%$ & $13 / 32 \%$ \\
\hline 8 & 6 & $3 / 10 \%$ & $3 / 7 \%$ \\
\hline \multicolumn{4}{|l|}{ Risk group $(n / \%)$} \\
\hline Low & $36 / 51 \%$ & $14 / 48 \%$ & $23 / 56 \%$ \\
\hline Intermediate & $22 / 31 \%$ & $11 / 38 \%$ & $10 / 24 \%$ \\
\hline High & $12 / 17 \%$ & $4 / 14 \%$ & $8 / 20 \%$ \\
\hline \multicolumn{4}{|c|}{ Maximum baseline GU toxicity grade $(n / \%)$} \\
\hline I & $36 / 51 \%$ & $16 / 55 \%$ & $20 / 49 \%$ \\
\hline II & $9 / 13 \%$ & $3 / 10 \%$ & $6 / 15 \%$ \\
\hline \multicolumn{4}{|c|}{ Treatment groups $(n / \%)$} \\
\hline Monotherapy & $47 / 67 \%$ & $20 / 69 \%$ & $27 / 66 \%$ \\
\hline Neoadjuvant & $23 / 33 \%$ & $9 / 31 \%$ & $14 / 34 \%$ \\
\hline \multicolumn{4}{|c|}{ Consecutive treatment days (Mon-Fri) $(n / \%)$} \\
\hline Consecutive days & $12 / 17 \%$ & $4 / 14 \%$ & $8 / 20 \%$ \\
\hline
\end{tabular}

who died from causes other than prostate cancer or treatment 34 months after SBRT. Neoadjuvant androgen deprivation therapy (ADT) in the form of luteinizing hormone-releasing hormone agonist was used in $33 \%$ of patients. The use of ADT was dependent on individual urologist and radiation oncologist preference, however, the percentage of the intermediate- and high-risk patients receiving hormones in the neoadjuvant and monotherapy groups were similar. Selected low-risk patients received ADT to shrink the prostate before SBRT. Eight patients received ADT for $\geq 24$ months, 13 for 6-24 months, and 2 for $<6$ months. Patients treated with SBRT plus ADT are termed the "neoadjuvant group" and those treated with SBRT exclusively the "monotherapy group." Patients who received 35 Gy or 36.25 Gy are termed the "low dose group" and those who received 37.5 Gy the "high-dose group." Tumor stage, Gleason score, risk group, consecutive treatment days and ADT usage were not significantly different between dose groups.

Twenty-nine patients (41\%) received $37.5 \mathrm{~Gy}, 36$ patients $(51 \%)$ received $36.25 \mathrm{~Gy}$, and five patients $(7 \%)$ received 35 Gy. Most patients received their treatment over 7 days (45\%), with the next highest proportion receiving treatment over 5 days $(17 \%)$, followed by those on treatment for 8 days (12\%). The remainder completed treatment between 9 and 15 days with one non-compliant patient receiving his final fraction several weeks later, all due to poor adherence to their schedule. Treatment was delivered with an average of $187(\mathrm{SD}=43.0)$ non-coplanar beams. X- 
ray images were taken every three to five beams to track the prostate's movement.

PSA response and biochemical control

PSA values began to gradually decline shortly after SBRT. The low-dose and high-dose groups' median PSA nadirs to date were 0.3 and $0.2 \mathrm{ng} / \mathrm{ml}$, respectively (Table 2). Three patients (4.2\%), all in the low dose group (Table 3), experienced $\mathrm{BF}$; two were high-risk and one intermediate-risk, despite the shorter median follow-up in the low-dose group (27 vs. 37 months). Overall 3-year actuarial FFBF was $94.5 \%$ (Fig. 2a). A dose response was observed for the intermediate- and high-risk patients $(p=0.0363$ ) with 3-year actuarial FFBF rates of $72 \%$ for the low dose group and $100 \%$ for the high dose group (Fig. 2b). Inclusion of lowrisk patients showed a dose response trend $(p=0.0775)$. Three-year FFBF rates were $100 \%, 95.0 \%$ and $77.1 \%$ for the low-, intermediate- and high-risk groups, respectively $(p=0.0530)$ (Fig. 2c). Neoadjuvant ADT in the high-, intermediate, and low-risk groups was used in $58 \%$, $50 \%$, and $14 \%$ of patients, respectively.

In the monotherapy group (median follow-up 29 months), the two patients with BF (one high- and one intermediaterisk; dose $36.25 \mathrm{~Gy}$ ) experienced time to biochemical failure (TTBF) at 24 and 17 months. One had a bone scan suggestive of metastatic spread and received $8 \mathrm{~Gy} \times 3$ fractions to the right ischium. The monotherapy group also includes five patients $(9 \%)$ with a benign PSA bounce at a median time of 19 months (range 16-20) after SBRT. Of those patients without BF, the median PSA nadir was $0.4 \mathrm{ng} / \mathrm{ml}$ (range 0.05 $2.9 \mathrm{ng} / \mathrm{ml}$ ). The largest proportion of PSA nadirs were $>0.1$ but $\leq 0.5 \mathrm{ng} / \mathrm{ml}$ (Table 2). Median PSA at most recent followup in the monotherapy group patients who did not experience $\mathrm{BF}(n=45)$ was $0.4 \mathrm{ng} / \mathrm{ml}$.

In the neoadjuvant group, the sole failure occurred 21 months following SBRT with metastasis to the thoracic spine. This high-risk patient received ADT $>24$ months and a SBRT dose of 35 Gy. Subsequently, this patient was treated with additional ADT, chemotherapy, and palliative radiotherapy. Ninety-one percent of PSA nadirs were $<0.1 \mathrm{ng} / \mathrm{ml}$, influenced heavily by hormonal effects. No benign PSA bounces occurred.
Toxicity

Acute genitourinary (GU) toxicity was moderate and rates were similar in each dose group (Table 4). Acute grade II GU toxicities were seen in $19 \%(n=13)$, of which nine patients were in the low dose group and 4 were in the high dose group. Acute grade III GU toxicities were observed in $4 \%(n=3)$, of which two patients were in the low dose group and one patient was in the high dose group. Two of the three grade III acute GU toxicities were frequency at least every hour and one was gross hematuria. These toxicities resolved within 3 months of treatment. However, one case of frequency at least every hour reappeared as a late toxicity. Acute gastrointestinal (GI) toxicity was limited to $4 \%$ grade II toxicity.

Late toxicity rates were acceptable with severe grade III toxicity occurring in only two patients (Table 4 ). Late grade II GU toxicities were observed in $29 \%(n=20)$, of which 13 patients were in the low dose group and seven were in the high dose group. Late grade III GU toxicities were observed in $3 \%(n=2)$, of which both patients were in the high dose group. One patient with a $162 \mathrm{~cm}^{3} \mathrm{CTV}$ (the largest prostate in our patient sample) had acute grade III frequency that resolved within 2 weeks of alpha-blocker and prophylactic antibiotic treatment, but recurred 6 months later. His symptoms improved to grade II immediately after trans-urethral resection of the prostate (TURP) 13 months after SBRT. Pathology of the resected tissue was negative for tumor. The second patient with late grade III GU toxicity experienced urinary retention. He had benign prostate hypertrophy (BPH) and grade II symptoms at baseline. At 14 months following SBRT, his symptoms progressed to grade III then completely subsided following laser TURP. Late GI toxicity was limited to $4 \%$ grade II toxicity. At most recent followup, no patient was experiencing grade III or higher toxicity. The most severe persistent toxicities are grade II GU (19\%) and GI (4 \%) with no difference by dose group.

Erectile dysfunction (ED) was assessed for the 29 monotherapy patients who were potent before SBRT. At last follow-up, $17 \%$ lost the ability to achieve erections strong enough for penetration and required ED medication for intercourse. No monotherapy patient who was potent before SBRT developed ED refractory to medical treatment.
Table 2 PSA nadir for patients in the monotherapy group without biochemical failure separated by risk group

\begin{tabular}{llllll}
\hline & $\begin{array}{l}\leq 0.1 \\
\mathrm{ng} / \mathrm{ml}\end{array}$ & $\begin{array}{l}0.1<x \leq 0.5 \\
\mathrm{ng} / \mathrm{ml}\end{array}$ & $\begin{array}{l}0.5<x \leq 1.0 \\
\mathrm{ng} / \mathrm{ml}\end{array}$ & $\begin{array}{l}1.0<x \leq 1.5 \\
\mathrm{ng} / \mathrm{ml}\end{array}$ & $\begin{array}{l}>1.5 \\
\mathrm{ng} / \mathrm{ml}\end{array}$ \\
\hline Monotherapy, $\mathrm{n}=47$ & $8 / 17 \%$ & $25 / 53 \%$ & $7 / 15 \%$ & $2 / 4 \%$ & $5 / 11 \%$ \\
Low, $n=32$ & $6 / 19 \%$ & $15 / 47 \%$ & $6 / 19 \%$ & $2 / 6 \%$ & $3 / 9 \%$ \\
Int, $n=10$ & $1 / 10 \%$ & $6 / 60 \%$ & $1 / 10 \%$ & & $2 / 20 \%$ \\
High, $n=5$ & $1 / 20 \%$ & $4 / 80 \%$ & & & \\
\hline
\end{tabular}


Table 3 PSA response and toxicity by dose group

\begin{tabular}{|c|c|c|c|c|c|}
\hline \multirow[t]{2}{*}{ Dose group } & \multirow{2}{*}{$\begin{array}{l}\text { Median follow-up } \\
\text { (months) }\end{array}$} & \multirow{2}{*}{$\begin{array}{l}\text { Biochemical } \\
\text { Failure (n) }\end{array}$} & \multirow{2}{*}{$\begin{array}{l}\text { Median PSA nadir } \\
\text { to date }(\mathrm{ng} / \mathrm{ml})\end{array}$} & \multicolumn{2}{|c|}{ Late GU toxicity } \\
\hline & & & & Grade II & Grade III \\
\hline High dose, $n=29$ & $37(24-48)$ & 0 & 0.2 & $7 / 24 \%$ & $2 / 7 \%$ \\
\hline Low dose, $n=41$ & $27(13-51)$ & 3 & 0.43 & $13 / 32 \%$ & 0 \\
\hline
\end{tabular}

\section{Discussion}

The 3-year actuarial FFBF rates of $100 \%, 95.0 \%$ and $77.1 \%$ for low-, intermediate- and high-risk groups and

a

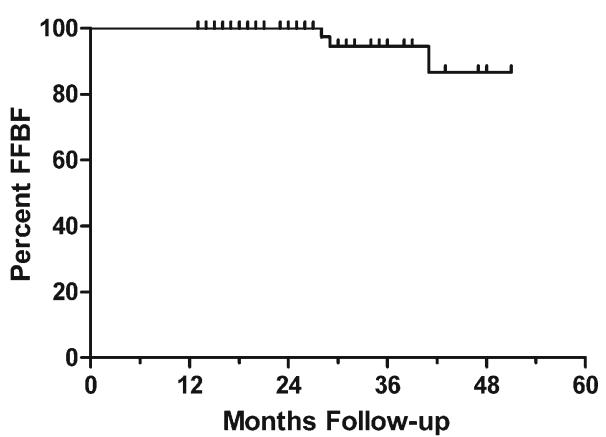

Pts @ risk: $70 \quad 70 \quad 46 \quad 18 \quad 3$

b

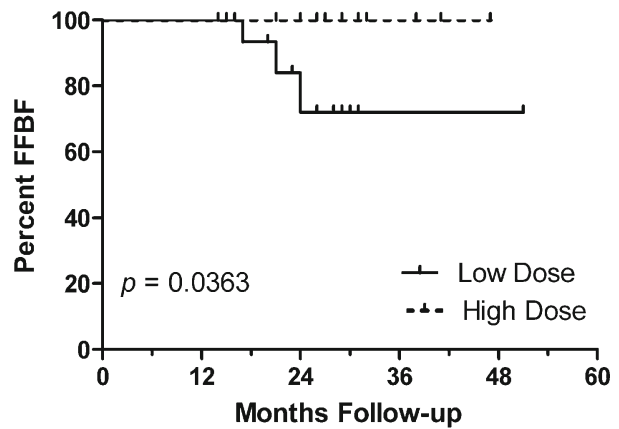

Pts@ risk

$\begin{array}{lllll}\text { low dose: } 18 & 18 & 7 & 2 & 2 \\ \text { high dose: } 16 & 16 & 14 & 8 & 2\end{array}$

C

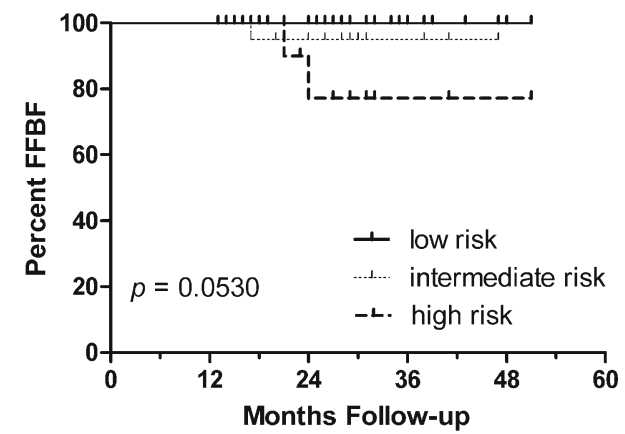

Pts@ risk

$\begin{array}{rcccc}\text { low: } 36 & 36 & 24 & 9 & 2 \\ \text { int: } 22 & 22 & 14 & 7 & 2 \\ \text { high: } 12 & 12 & 7 & 3 & 2\end{array}$

Fig. 2 FFBF for a all patients, b intermediate- and high-risk patients by dose group and $\mathbf{c}$ all patients by risk group overall toxicity are concordant with published SBRT outcomes (Table 5). We further analyzed patients separately as those who received neoadjuvant ADT and those who received SBRT monotherapy due to the confounding effect that hormonal therapy can have on obscuring true PSA decline and $\mathrm{BF}$ rates. While our study lacks the long-term follow-up essential to make conclusions regarding rates of $\mathrm{BF}$, it does offer sufficient follow-up to evaluate nadir PSA to date.

Zelefsky et al. [23] showed that 24-month nadir PSA was predictive of distant recurrence. They reported that patients who fail to achieve a nadir PSA $<1.5 \mathrm{ng} / \mathrm{ml}$ within 24 months have a higher propensity for relapsing disease. Lamb et al. [24] further support that the nadir PSA is the strongest prognostic indicator of all early PSA-based indicators with the ability to predict long-term survival. We regard the low nadir PSA in our series as indicative of a favorable outcome despite the limited follow-up. For example, our monotherapy data show $86 \%$ of patients with $>24$ months follow-up reached a nadir $<1.5 \mathrm{ng} / \mathrm{ml}$ before 24 months post-SBRT. We report the nadir PSA to date of the high dose group to be less than that of

Table 4 Acute and late maximum toxicity assessed by the RTOG toxicity scale

\begin{tabular}{lrcr}
\hline & Grade I & Grade II & Grade III \\
\hline Acute toxicity & & & \\
GU & $39 / 56 \%$ & $13 / 19 \%$ & $3 / 4 \%$ \\
Low dose & $22 / 54 \%$ & $9 / 22 \%$ & $2 / 5 \%$ \\
High dose & $17 / 59 \%$ & $4 / 14 \%$ & $1 / 3 \%$ \\
GI & $12 / 17 \%$ & $3 / 4 \%$ & $0 \%$ \\
Low dose & $8 / 20 \%$ & $3 / 7 \%$ & \\
High dose & $4 / 14 \%$ & & \\
Late toxicity & & & \\
GU & $31 / 44 \%$ & $20 / 29 \%$ & $2 / 3 \%$ \\
Low dose & $17 / 41 \%$ & $13 / 32 \%$ & \\
High dose & $14 / 48 \%$ & $7 / 24 \%$ & $0 \%$ \\
GI & $7 / 10 \%$ & $6 / 9 \%$ & \\
Low dose & $4 / 10 \%$ & $4 / 10 \%$ & \\
High dose & $3 / 10 \%$ & $2 / 7 \%$ & \\
ED & $8 / 28 \%$ & $5 / 17 \%$ & $0 \%$ \\
Low dose & $4 / 25 \%$ & $3 / 19 \%$ & \\
High dose & $4 / 31 \%$ & $2 / 15 \%$ & \\
\hline
\end{tabular}

${ }^{\mathrm{a}}$ ED assessed by CTCAE v3 
Table 5 SBRT publications for primary treatment of prostate cancer

\begin{tabular}{|c|c|c|c|c|c|c|c|}
\hline Author & Dose scheme & $\begin{array}{l}\text { No. of } \\
\text { patients }\end{array}$ & $\begin{array}{l}\text { Risk } \\
\text { group }\end{array}$ & $\begin{array}{l}\text { Median } \\
\text { follow-up } \\
\text { (mo) }\end{array}$ & $\begin{array}{l}\text { Freedom from } \\
\text { biochemical failure } \\
\text { (by risk) }\end{array}$ & $\begin{array}{l}\text { Late grade III } \\
\text { GU/GI Toxicity }\end{array}$ & $\begin{array}{l}\text { Patients receiving } \\
\text { ADT }\end{array}$ \\
\hline $\begin{array}{l}\text { Oliai et al. } \\
2012\end{array}$ & $\begin{array}{l}7.0,7.25 \text { and } \\
7.5 \mathrm{~Gy} \times 5\end{array}$ & 70 & $\begin{array}{l}\text { low, int, } \\
\text { high }\end{array}$ & 31 & $\begin{array}{r}100 \%, 94.7 \% \\
77.1 \% 3 \text {-year }\end{array}$ & $3 \% / 0 \%$ & $33 \%$ \\
\hline $\begin{array}{l}\text { King et al. } \\
2012\end{array}$ & $7.25 \mathrm{~Gy} \times 5$ & 67 & low & 32 & $94 \%$ 4-year & $3 \% / 0 \%$ & none \\
\hline $\begin{array}{l}\text { McBride et } \\
\text { al. } 2011\end{array}$ & $\begin{array}{l}7.25 \text { and } \\
7.5 \mathrm{~Gy} \times 5\end{array}$ & 45 & low & 44 & $97.7 \% 3$-year & $2 \% / 5 \%$ & $\begin{array}{l}\text { none (within } 6 \text { months } \\
\text { of treatment) }\end{array}$ \\
\hline $\begin{array}{l}\text { Boike et al. } \\
2011\end{array}$ & $\begin{array}{r}9,9.5 \text {, and } \\
10 \mathrm{~Gy} \times 5\end{array}$ & 45 & low, int & $30 / 18 / 12$ by dose & $100 \%$ & $4 \% / 2 \%($ Gr 4$)$ & $22 \%$ \\
\hline $\begin{array}{l}\text { Kang et al. } \\
2011\end{array}$ & $\begin{array}{c}8,8.5 \text {, and } \\
9 \mathrm{~Gy} \times 4\end{array}$ & 44 & $\begin{array}{l}\text { low, int, } \\
\text { high }\end{array}$ & 40 & $\begin{array}{l}100 \%, 100 \% \\
90.8 \%\end{array}$ & $0 \% / 0 \%$ & $87 \%$ \\
\hline $\begin{array}{l}\text { Freeman et } \\
\text { al. } 2011\end{array}$ & $\begin{array}{l}7 \text { and } \\
7.25 \mathrm{~Gy} \times 5\end{array}$ & 41 & low & 60 & $92.7 \%$ 5-year & $2.5 \% / 0 \%$ & none \\
\hline $\begin{array}{l}\text { Bolzicco et } \\
\text { al. } 2010\end{array}$ & $7 \mathrm{~Gy} \times 5$ & 45 & low, int & 20 & $100 \%$ & $2.2 \% / 0 \%$ & $38 \%$ \\
\hline $\begin{array}{l}\text { Katz et al. } \\
2010\end{array}$ & $\begin{array}{l}7 \text { and } \\
7.25 \mathrm{~Gy} \times 5\end{array}$ & 304 & $\begin{array}{l}\text { low, int, } \\
\text { high }\end{array}$ & 30 & $\begin{array}{c}99 \%, 84 \% \\
100 \%\end{array}$ & $<1 \% / 0 \%$ & $19 \%$ \\
\hline $\begin{array}{l}\text { Friedland et } \\
\text { al. } 2009\end{array}$ & $\begin{array}{l}7 \text { and } \\
7.25 \mathrm{~Gy} \times 5\end{array}$ & 112 & $\begin{array}{l}\text { low, int, } \\
\text { high }\end{array}$ & 24 & $97.3 \%$ & $0 \% /<1 \%$ & $19 \%$ \\
\hline $\begin{array}{l}\text { Madsen et } \\
\text { al. } 2007\end{array}$ & $6.7 \mathrm{~Gy} \times 5$ & 40 & low & 41 & $90 \%$ 4-year & $0 \% / 0 \%$ & none \\
\hline
\end{tabular}

the low dose group $(0.2$ vs. $0.3 \mathrm{ng} / \mathrm{ml})$. It is important to note that the median follow-up for the high dose group is 10 months greater than the low dose group. Therefore, the patients receiving high dose had additional time for their PSA to fall.

It is worth commenting on the median PSA at most recent follow-up, despite the relatively slow-growing nature of prostate cancer. At a median follow-up of 32 months, King et al. report a low median PSA at most recent follow-up of $0.5 \mathrm{ng} / \mathrm{ml}$ in low-risk patients who did not receive ADT. Our results are similar in the monotherapy group (low-, intermediate-, high-risk patients), which have a median PSA at most recent follow-up of $0.4 \mathrm{ng} / \mathrm{ml}$ at a median follow-up of 29 months. Although the patients have several more years to experience BF, these PSA values have reached low levels in a short duration, which may be an indication of favorable long-term control.

Figure $2 \mathrm{~b}$ represents a dose response in intermediate- and high-risk groups, which had similar proportion of patients receiving neoadjuvant ADT in each group (50 \% vs. $58 \%$ ). Few other SBRT publications [16, 17] provide outcomes stratified by intermediate- and high-risk. In the case of IMRT, Zelefsky et al. report an 8-year FFBF rate of $67 \%$ for high-risk patients receiving 81 Gy IMRT with conventional fractionation. While this is a longer follow-up than the current study, it is important to note that the decline in FFBF between 3 and 8 years was modest (approximately $77 \%$ vs. $67 \%$ ), most likely due to the tendency of early failure for high-risk prostate cancer patients [25]. Thus, the current report's observed $77 \%$ 3-year FFBF rate for high-risk patients suggests SBRT may have a role in the treatment of these patients. In regard to intermediate-risk patients treated with SBRT, Katz et al. has presented data with 4-year actuarial FFBF of $91 \%$ in those with intermediate risk disease treated with 35-36.25 Gy plus $28 \%$ receiving ADT. The rate of late grade III GU toxicity was $1.2 \%$ and median PSA at 46 month follow-up was $0.1 \mathrm{ng} / \mathrm{ml}$ [26]. Furthermore, randomized conventionally fractionated dose-escalation trials have shown dose responses for intermediate- and high-risk patients [4, 27] similar to those observed here, but limited SBRT dose escalation results exist.

Katz et al. [28] reported comparable efficacy in primarily low-risk patients treated with 35 and 36.25 Gy. Their results indicate a trend toward higher late GU toxicity as dose increases, which is also a trend in our study with respect to late grade III GU toxicity but not grade II toxicity (Table 4). Boike et al. [21] report dose escalation of 45, 47.5 and 50 Gy for low- and intermediate-risk patients using 3-mm PTV margins. At 30 months median follow-up, the 15 patients receiving 45 Gy experienced similar toxicity and efficacy compared to the other SBRT publications. Our observed dose escalation benefit for intermediate- and high-risk patients includes slightly higher late grade III GU toxicity, but no significant difference in GI toxicity. One of the patients with late grade III GU toxicity had the largest prostate volume in the study (3.5 times larger than the median volume), which may have contributed to the severity of his toxicity. While Boike et al. do not report a dose limiting toxicity, their only grade IV event occurred in their highest dose group - a group which had 12 months 
median follow-up, suggesting this group's toxicity rate will likely increase. It is also important to note that our treatment is delivered with the CyberKnife, which tracks the fiducial position throughout treatment whereas Boike et al. track fiducials prior to each treatment, not during delivery. As dose increases and PTV margin decreases tracking prostate motion during treatment becomes more important to ensure nearby critical structure dose is limited and target dose is not compromised. Nonetheless, their use of a balloon may substantially limit the movement of the prostate with the risk of higher doses to the anterior rectum.

In the prospective study by King et al. [18], there was a significant reduction in the rate of late grade I toxicities in the subset of patients treated every other day (QOD). There may be a benefit for QOD vs. daily fractionation, however, this phenomenon was not well understood in terms of radiobiology. At the time when our patients were treated, QOD fractions were not used. After analyzing radiobiological models with prominent radiobiologists in late 2008 , we have since decided to incorporate at least a 1-day break between treatments, which includes some patients in this study.

Toxicities from IMRT to the prostate have been well documented. Zelefsky et al. [25] report long-term data on late toxicity using an IMRT dose of 81 Gy given in traditional fractionation. At a median follow-up of 7 years with 561 patients, $3 \%$ of patients experienced late grade III GU toxicity (according to the Common Terminology Criteria of Adverse Events toxicity scale) and $9 \%$ had late grade II GU toxicity occurring at a median of 14 months after completion of IMRT. Late GI toxicity manifested in less than $1 \%$ as grade III and $1.5 \%$ as grade II at a median of 13 months after IMRT completion. Our current study shows the same proportion of late grade III GU toxicity and similar late GI toxicity. We roughly compare late toxicity rates despite the difference in length of follow-up between the studies since their median time to late toxicity was 14 months. In a study with similar length of follow-up, Eade et al. report late toxicities in patients treated with IMRT doses of 74-78 Gy or I-125 brachytherapy. Their 3-year actuarial risk of acute and late GU toxicities from IMRT were $1.4 \%$ and $0.5 \%$, respectively. There were no acute or late grade III GI toxicities [29].

Reported potency preservation rates for SBRT include $40 \%$ at 35 months [28] and $80-82 \%$ at 1 year $[16,17]$. Wiegner and King [30] compared ED rates following SBRT to other modalities of radiotherapy alone and concluded ED rates in the proportion of patients receiving SBRT to be similar to the upper end experienced by those receiving other types of monotherapy. In the current study, at a median 31 months $83 \%$ of monotherapy patients remained potent. Importantly, usage of ED medications increases this potency preservation rate to $100 \%$. Nevertheless, comparison of published potency rates is difficult because different metrics are used and ED medication usage is not uniformly reported.

\section{Conclusions}

These results support the growing body of literature indicating SBRT for prostate cancer is effective and well tolerated with excellent FFBF, PSA nadirs, and acceptable toxicity. The potential benefits of dose escalation in intermediateand high-risk patients suggest SBRT offers promise for a treatment that has improved convenience, low toxicity, excellent clinical outcomes and likely reduced cost. One limitation of our current study is that BF was not confirmed as local failure by prostate biopsy. This makes it difficult to draw strong conclusions regarding a dose response. We can conclude that dose escalation may be beneficial in specific patient groups, in order to influence future study design. Prospective trials for prostate cancer studying SBRT regimens with long-term follow-up and prostate biopsies to confirm local failure in those with BF are needed to confirm it as an alternative treatment in comparison to IMRT and radical prostatectomy. There is currently a randomized phase II SBRT trial (RTOG 0938) accruing favorable-risk prostate cancer to hypofractionated schedules of $7.25 \mathrm{~Gy} \times$ 5 and $4.3 \mathrm{~Gy} \times 12$. Decisions regarding the optimal treatment will eventually become clearer when data from the randomized trial Prostate Advances in Comparative Evidence compares IMRT to SBRT and SBRT to surgery.

Acknowledgments We thank Pam Commike, PhD (Accuray Incorporated), for editorial assistance.

Conflict of interest The authors Dr. Lanciano, Dr. Lamond, Dr. Arrigo, and Dr. Brady each own a small percentage of the single unit Cyberknife used at the Philadelphia Cyberknife Center.

Open Access This article is distributed under the terms of the Creative Commons Attribution License which permits any use, distribution, and reproduction in any medium, provided the original author(s) and the source are credited.

\section{References}

1. Hanks GE, Hanlon AL, Epstein B, Horwitz EM (2002) Dose response in prostate cancer with 8-12 years' follow-up. Int J Radiat Oncol Biol Phys 54:427-435

2. Zelefsky MJ, Yamada Y, Fuks Z et al (2008) Long-term results of conformal radiotherapy for prostate cancer: impact of dose escalation on biochemical tumor control and distant metastases-free survival outcomes. Int $\mathrm{J}$ Radiat Oncol Biol Phys 71:1028-1033

3. Dearnaley DP, Sydes MR, Graham JD et al (2007) Escalated-dose versus standard-dose conformal radiotherapy in prostate cancer: first results from the MRC RT01 randomised controlled trial. Lancet Oncol 8:475-487

4. Peeters ST, Heemsbergen WD, Koper PC et al (2006) Doseresponse in radiotherapy for localized prostate cancer: results of the Dutch multicenter randomized phase III trial comparing 68 Gy of radiotherapy with 78 Gy. J Clin Oncol 24:1990-1996 
5. Kuban DA, Tucker SL, Dong L et al (2008) Long-term results of the M. D. Anderson randomized dose-escalation trial for prostate cancer. Int J Radiat Oncol Biol Phys 70:67-74

6. Brenner DJ, Hall EJ (1999) Fractionation and protraction for radiotherapy of prostate carcinoma. Int J Radiat Oncol Biol Phys 43:1095-1101

7. Fowler J, Chappell R, Ritter M (2001) Is alpha/beta for prostate tumors really low? Int J Radiat Oncol Biol Phys 50:1021-1031

8. Lukka H, Hayter C, Julian JA et al (2005) Randomized trial comparing two fractionation schedules for patients with localized prostate cancer. J Clin Oncol 23:6132-6138

9. Pollack A, Hanlon AL, Horwitz EM et al (2006) Dosimetry and preliminary acute toxicity in the first 100 men treated for prostate cancer on a randomized hypofractionation dose escalation trial. Int J Radiat Oncol Biol Phys 64:518-526

10. Yeoh EE, Holloway RH, Fraser RJ et al (2006) Hypofractionated versus conventionally fractionated radiation therapy for prostate carcinoma: updated results of a phase III randomized trial. Int J Radiat Oncol Biol Phys 66:1072-1083

11. Dasu A (2007) Is the alpha/beta value for prostate tumours low enough to be safely used in clinical trials? Clin Oncol (R Coll Radiol) 19:289-301

12. Miralbell R, Roberts SA, Zubizarreta E, Hendry JH (2012) Dosefractionation sensitivity of prostate cancer deduced from radiotherapy outcomes of 5,969 patients in seven international institutional datasets: alpha/beta=1.4 (0.9-2.2) Gy. Int J Radiat Oncol Biol Phys 82:e17-e24

13. Martinez AA, Demanes J, Vargas C, Schour L, Ghilezan M, Gustafson GS (2010) High-dose-rate prostate brachytherapy: an excellent accelerated-hypofractionated treatment for favorable prostate cancer. Am J Clin Oncol 33:481-488

14. Bolzicco G, Favretto MS, Scremin E, Tambone C, Tasca A, Guglielmi R (2010) Image-guided stereotactic body radiation therapy for clinically localized prostate cancer: preliminary clinical results. Technol Cancer Res Treat 9:473-477

15. Freeman DE, King CR (2011) Stereotactic body radiotherapy for low-risk prostate cancer: five-year outcomes. Radiat Oncol 6:3

16. Friedland JL, Freeman DE, Masterson-McGary ME, Spellberg DM (2009) Stereotactic body radiotherapy: an emerging treatment approach for localized prostate cancer. Technol Cancer Res Treat $8: 387-392$

17. Katz AJ, Santoro M, Ashley R, Diblasio F, Witten M (2010) Stereotactic body radiotherapy for organ-confined prostate cancer. BMC Urol 10:1

18. King CR, Brooks JD, Gill H, Presti JC Jr (2012) Long-term outcomes from a prospective trial of stereotactic body radiotherapy for low-risk prostate cancer. Int J Radiat Oncol Biol Phys 82:877-882
19. McBride SM, Wong DS, Dombrowski JJ et al (2011) Hypofractionated stereotactic body radiotherapy in low-risk prostate adenocarcinoma: preliminary results of a multi-institutional phase 1 feasibility trial. Cancer. doi:10.1002/cncr.26699

20. Kang JK, Cho CK, Choi CW et al (2011) Image-guided stereotactic body radiation therapy for localized prostate cancer. Tumori 97:43-48

21. Boike TP, Lotan Y, Cho LC et al (2011) Phase I dose-escalation study of stereotactic body radiation therapy for low- and intermediate-risk prostate cancer. J Clin Oncol 29:2020-2026

22. Madsen BL, Hsi RA, Pham HT, Fowler JF, Esagui L, Corman J (2007) Stereotactic hypofractionated accurate radiotherapy of the prostate (SHARP), 33.5 Gy in five fractions for localized disease: first clinical trial results. Int J Radiat Oncol Biol Phys 67:10991105

23. Zelefsky MJ, Shi W, Yamada Y et al (2009) Postradiotherapy 2year prostate-specific antigen nadir as a predictor of long-term prostate cancer mortality. Int J Radiat Oncol Biol Phys 75:13501356

24. Lamb DS, Denham JW, Joseph D et al (2011) A comparison of the prognostic value of early PSA test-based variables following external beam radiotherapy, with or without preceding androgen deprivation: analysis of data from the TROG 96.01 randomized trial. Int J Radiat Oncol Biol Phys 79:385-391

25. Zelefsky MJ, Chan H, Hunt M, Yamada Y, Shippy AM, Amols H (2006) Long-term outcome of high dose intensity modulated radiation therapy for patients with clinically localized prostate cancer. J Urol 176:1415-1419

26. Katz A, Santoro M, Diblasio F. (2012) Four year outcomes and quality of life following stereotactic body radiation therapy: a rapid, non-invasive alternative for the treatment of intermediaterisk organ confined prostate cancer. Oral presentation at the American Urological Association annual meeting; 1478. Atlanta, GA, 19-22 May 2012

27. Pollack A, Zagars GK, Starkschall G et al (2002) Prostate cancer radiation dose response: results of the M. D. Anderson phase III randomized trial. Int J Radiat Oncol Biol Phys 53:1097-1105

28. Katz AJ, Santoro M, Ashley R, Diblasio F (2011) Stereotactic body radiation therapy for low- and low-intermediate-risk prostate cancer: is there a dose effect? Front Oncol 1:49

29. Eade T, Horwitz E, Ruth K et al (2008) A Comparison of acute and chronic toxicity for men with low-risk prostate cancer treated with intensity-modulated radiation therapy or 125 I permanent implant. Int J Radiat Oncol Biol Phys 71:338-345

30. Wiegner EA, King CR (2010) Sexual function after stereotactic body radiotherapy for prostate cancer: results of a prospective clinical trial. Int J Radiat Oncol Biol Phys 78:442-448 